\title{
Obituaries
}

\section{Peter Scheuer}

Histopathologist who helped make London's Royal Free Hospital one of the world's leading centres for investigating liver disease

The 1940s and 1950s saw the emergence of liver biopsy as a major clinical investigative procedure. Peter Scheuer became one of the leading experts in the field, achieving world fame as a histopathologist and bringing distinction to himself, his medical school, and British pathology.

$\mathrm{He}$ was appointed lecturer in morbid anatomy at the Royal Free Hospital, London, in 1959, commencing his duties on the same day as the hepatologist Sheila Sherlock (obituary BMJ 2002;324:174) took up her position as professor of medicine. Professor Sherlock had already established a reputation in hepatology at the Hammersmith Hospital, and Peter had an interest in hepatopathology developed under the supervision of Professor Kenneth Hill. Peter provided a superb diagnostic hepatopathology service for the medical unit, resulting in the establishment of the Royal Free as one of the world's leading centres for the investigation of clinical liver disease.

In 1968 Peter published the first edition of Liver Biopsy Interpretation, a brief text, but written concisely and with great clarity, and it became the essential bench book for general histopathologists worldwide such that liver biopsies became less of a chore and more of a challenge. A seventh edition was published in 2005 (conjointly with Dr Jay Lefkowitch of Columbia University, New York).

Peter Joseph Scheuer was born in Hamburg in 1928 to Jewish Viennese parents. The family were members of a Lutheran church, but this was of no help because the Nazi authorities' concern was with ethnic origin. The family returned to Vienna in 1937, but after the annexation of Austria in March 1938 they had to make good their escape as individuals and not as a whole family. Peter and his mother joined his father in England in December 1938, their visa having one day to run when they departed.

After leaving school in 1947 Peter obtained a post as a laboratory technician in Bromley Cottage Hospital, where the consultant in charge encouraged him to consider medicine as a career. Peter gained a zoology higher school certificate, studying

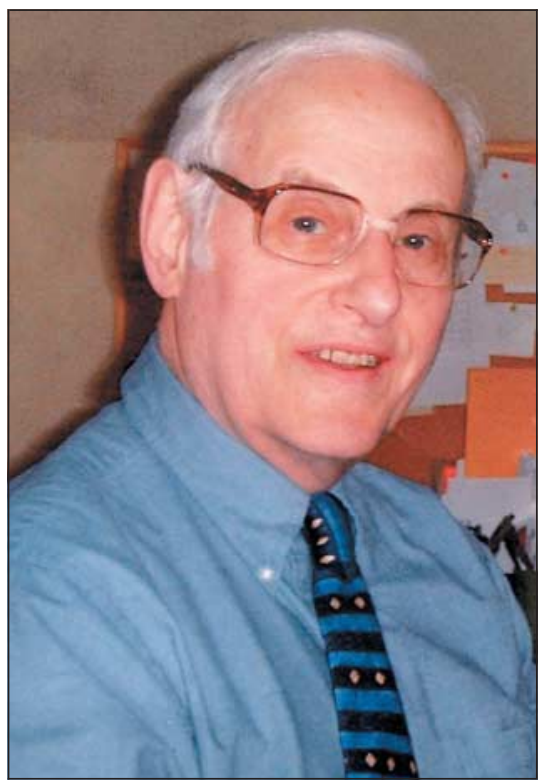

on a part time basis in London, and was admitted to the Royal Free School of Medicine in 1949, one of 12 males among some 80 females in the year. After qualifying and house jobs he was conscripted into the Royal Army Medical Corps, and spent two years in Singapore, where he developed an interest in laboratory medicine, and rose to the rank of captain.

He returned to a senior house officer post in pathology at the Royal Free and proceeded to complete an MD degree in 1961 on laboratory aspects of venoocclusive disease of the liver. In 1962 he obtained a British Postgraduate Federation fellowship and spent a year with Dr Hans Popper at the Mount Sinai Hospital in New York. Hans (also a Jewish refugee from Vienna) was already regarded as the world's foremost liver pathologist, and Peter returned from New York to a post of lecturer and with a broader vision and with new experience gained away from the Royal Free. His career blossomed and he obtained a personal professorship of clinical histopathology and, in September 1983, he became professor of pathology and head of department, a post that he held till his retirement in September 1992. He was the first male graduate of the school to become a consultant in the Royal Free and the first to hold a chair.

Peter was a member of the "Gnomes," a group of pathologists and clinicians who first met informally at the second meeting of the recently formed European Association of the Study of the Liver in Gothenburg in 1967; they again met in Zurich in 1968, and their paper "A Classification of Chronic Hepatitis," published in the Lancet the same year, became a citation classic. The paper owed much to Peter's skilled drafting of the deliberation and discussions by the group. The name "Gnomes" was of Sheila Sherlock's choosing, describing the group as manipulating the nomenclature of liver disease just as the Gnomes of Zurich, the bankers of Europe, manipulated the continent's finances.

Peter was co-editor of Pathology of the Liver, a fifth edition of which will appear in 2006 and is the recognised textbook in this discipline.

Outside pathology his major interest was in music. He started violin lessons in 1937 , continued this interest at school, and, while studying medicine, he attended classes at the London College of Music. He started cello lessons and soon became an accomplished performer, playing in an amateur orchestra and in piano trios and string quartets.

In 1960 he married Dr Louise Withington, a postdoctoral fellow in the department of anatomy at the Royal Free. She shared his musical interest and is an accomplished pianist.

He leaves Louise; two sons; and three granddaughters. [Roddy MACSwEen, Jim McLaughlin]

Peter Joseph Scheuer, professor of pathology Royal Free Hospital, London, 1983-92 (b Hamburg 1928; q Royal Free School of Medicine 1954), d 1 March 2006.

Longer versions of these obituaries are available on bmj.com 


\section{Helen Ann Adam (née Smith)}

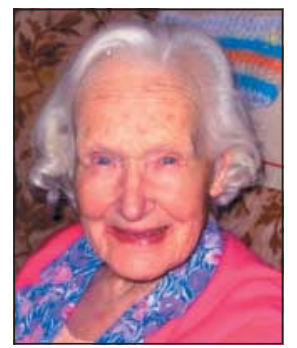

Former general practitioner Crosspool (b 1915 ; q Aberdeen 1939), d 26 December 2006.

Helen Ann Smith moved to house posts in Sheffield, where she met her future husband, John Adam. While John served overseas in the Royal Army Medical Corps, Helen returned to hospital work in Sheffield. After the second world war she and John practised together in Sheffield. She admitted herself to the Jessop Hospital on the day that her only child, John, was born only after she had completed her rounds. She moved to New Zealand and then Jamaica in the 1950 s, her health necessitating a return to Sheffield, where she joined the practice at Crosspool. She retired aged 70-under protest-from both practice and the BMA. [JAMEs Dickson]

\section{John Anderson}

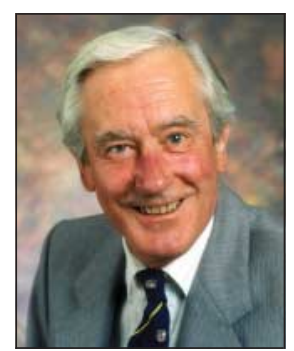

Former consultant orthopaedic surgeon

Cumberland Infirmary, Carlisle (b 1937;

q Aberdeen 1964; FRCS Ed), d 30 March 2006.

John Anderson was consultant orthopaedic surgeon at the Cumberland Infirmary until his early retirement in 1991. He gained the FRCS Ed in 1968. After further experience in Scotland and abroad he took up his final clinical post in 1974 . He was the first surgeon in East Cumbria to be trained in joint replacement therapy, and he helped to establish this service. Outside medicine he enjoyed sailing the lochs off the west of Scotland. He was a man who could be relied on even in the foulest Scottish weather. His wife, Jenny, died in 1991. [A A BRown]

\section{John Edward Dann Charles-Jones}

Former general practitioner and aviation medical examiner Chester (b 1930; q Charing Cross Hospital 1955), died from pancreatic cancer on 15 March 2006.

After a period in general practice he worked for the NHS for several years and developed

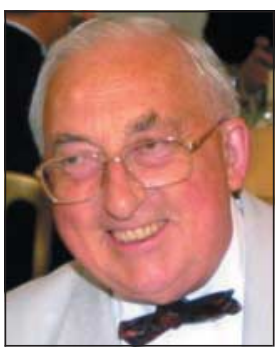

an interest in aviation medicine. He was a founder member and later chairman of the Association of Aeronautical Medical Examiners. In 1997 he was elected a fellow of the Royal Aeronautical Society. Forced by illness to retire in 1990 from the busy general practice he shared with his wife, he continued as an aviation medical examiner. A keen naturalist, he also spent many years as a scout leader. He leaves a wife, Shirley, and four children. [DAVID CAMPBELL]

\section{Roger Ernest Cotton}

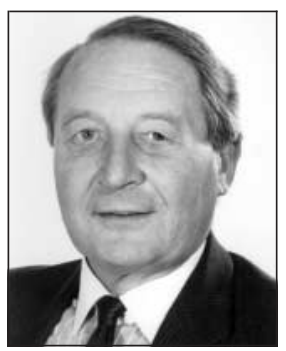

Emeritus consultant pathologist City Hospital, Nottingham, and special professor of diagnostic oncology University of Nottingham (b 1926; $q$ Middlesex Hospital 1949; MD, FRCPath), d 15 March 2006.

Roger was the foundation editor of Histopathology. Students at the Middlesex in the 1960s are indebted to him for his teaching of systemic pathology, his course with Drew Thompson forming the basis for Lecture Notes in Pathology. In 1963 Roger became a founder member of the College of Pathologists and was appointed consultant pathologist at the City Hospital, Nottingham, to establish a department almost from scratch. When he retired, in 1990, it had a national and international reputation. Roger became president of the British division of the International Academy of Pathology in 1977 and European vice president of the International Academy of Pathology in 1978. Predeceased by his first wife, Sheila, he leaves a second wife, Sue; two sons from his first marriage; and four grandchildren. [CHRISTOPHER Elston, Roger Blamey, John FLETCHER]

\section{George Anthony Knight ("Tony") Missen}

Former head of department of clinical microscopy (diagnostic histopathology), Guy's Hospital, London (b 1923; q Oxford 1946;DM, FRCPath, DCP), d November 2005.

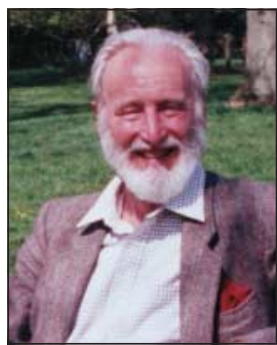

George Anthony Knight ("Tony") Missen joined the Royal Army Medical Corps on qualifying. After time in Singapore and Hong Kong he served at the Commonwealth General Hospital, Kure, Japan, during the Korean war. In 1951 Tony returned to England, where he joined the department of pathology at Guy's Hospital, ultimately running the department of clinical microscopy (diagnostic histopathology) until his retirement in 1988. On his retirement Tony was recruited to the Royal College of Surgeons/Imperial Cancer Research Fund Histopathology Unit. There he joined a group of distinguished histopathologists known to many as "the wise men." When this group was disbanded in 1997 Tony finally retired. He leaves a wife, Irene. [ANDREW M HANBy, Rosemary Millis]

\section{Anilkumar (“Anil”) Patel}

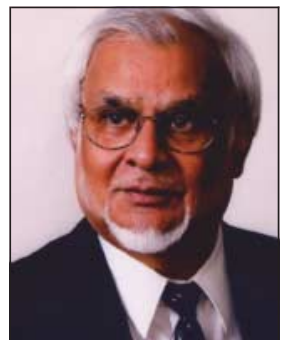

Former director Queensland Department of Specialised Health Services, Australia (b 1931; q Madras 1959; FRCP, FRACP), died from metastatic prostate cancer on 28 February 2006.

Anilkumar Patel ("Anil") was director of tuberculosis control for Uganda, consultant physician at Mulago Hospital, Kampala, and principal investigator for Uganda in the East African/British Medical Research Council's trials on short course treatment for pulmonary tuberculosis. Forced to leave Uganda under General Idi Amin's regime, Anil became regional thoracic physician in Cairns in 1973, establishing respiratory diseases services at district hospitals in North Queensland. He was appointed assistant director of tuberculosis in Queensland in 1979, then director of specialised health services in 1984 until his retirement in 2002. In 2003 he was awarded Queensland's Public Service Medal for outstanding service in health and the control of tuberculosis. He leaves a wife, Nalini, and two children. [Krishna Somers] 